\section{Structure of Epistilbite}

AfTER the determination of the related structures of mordenite ${ }^{1}$ and dachiardite ${ }^{2}$, attempts were made to find other related frameworks ${ }^{3}$ corresponding to known minerals. Continuing this work, it appears that a modification of the mordenite chains results in a structure fitting the requirements of epistilbite. Figs. $1 A$ and $B$ show the arrangement-observing the usual convention of indicating only silicon and aluminium atoms which fall at the corners, while the oxygens of the framework lie close to the mid-points of each line. Fig. $1 A$ shows the structure projected down the $a$-axis, which owing to superposition of certain vertical bonds should be interpreted with the assistance of Fig. I $B$ showing a single layer seen along the $b$-axis.

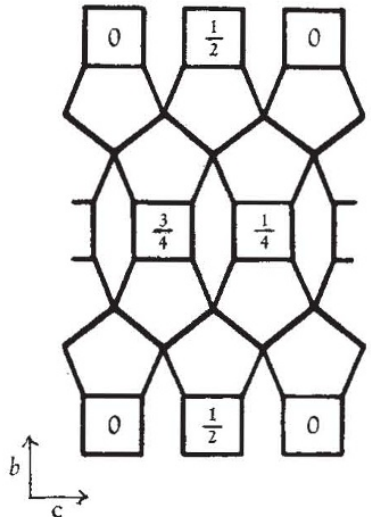

$A$

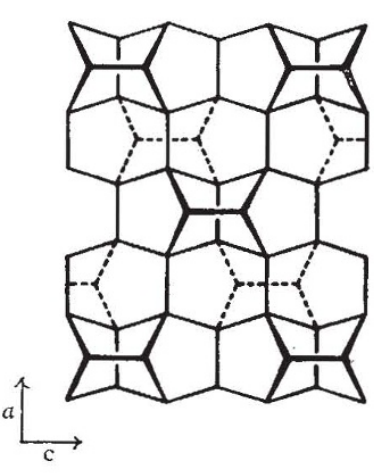

$B$
Fig. 1. $A, a$-projection of the structure. Silicons in the zig-zag layer superpose four times while those of the four-membered rings occur once.

There is a relationship between the pseudorhombic cell of epistilbite and the orthorhombic cell of mordenite as follows:

$$
\begin{aligned}
& \text { Epistilbite } a=14 \cdot 80 ; \quad b=17 \cdot 73 ; c=10 \cdot 21 \AA ; \quad \beta=90^{\circ} 35^{\prime} \\
& \text { Mordenite } c=7 \cdot 52 ; \quad a=18 \cdot 13 ; b=20 \cdot 49 \AA
\end{aligned}
$$

where it can be seen that the chain repeat distance is doubled in epistilbite ( $a$-axis) and one other axis is halved. Both cells contain 48 silicon + aluminium atoms. The symmetry of this suggested structure is $C 2 / \mathrm{m}$ for the monoclinic cell. In the pseudo-rhombic cell, used here for convenience, there are additional lattice points at $\frac{1}{2} 0 \frac{1}{2}$, $\frac{3}{4} \frac{1}{2} \frac{1}{6}$ and $\frac{1}{4} \frac{1}{2} \frac{3}{4}$. The approximate co-ordinates of silicon and aluminium atoms are:

$$
\begin{array}{llll}
\mathrm{Si} / \mathrm{Al} & \pm 0.145 & 0.196 & 0.232 \\
\mathrm{Si} / \mathrm{Al} & 0 & 0.088 & 0.156
\end{array}
$$

Calculated X-ray diffraction intensities agree well with the powder pattern data and extinctions occur where predicted.

This structure for epistilbite possesses ellipsoidal cavities roughly $12 \times 8.4 \times 3.7 \AA^{3}$, which are linked through 8-membered ring windows to form a two-dimensional network of channels in the $a c$-plane. The free passage of these elliptical windows is about $4.8 \times 3.8 \AA$. The proposed framework would also account for two further properties: (1) the similarity of the powder patterns of epistilbite and dachiardite, to which it is more closely related than mordenite; (2) the flakiness and (010) cleavage of epistilbite as opposed to the fibrous habits of mordenite and dachiardite, due to strengthening of the bonding in the $c$-direction.

The structural layers may be stacked in different ways, so that two rhombic structures with $b=35.4 \AA$ may be built by translating certain sets of 4-membered rings by $\frac{1}{2} a$. Twinning may also occur.
I thank Prof. R. M. Barrer for his advice.

Department of Chemistry.

IAN S. KERR

Imperial College of Science and Technology, London, S.W.7.

${ }^{1}$ Meier, W. M., Z. Krist., 115, 439 (1961).

${ }^{2}$ Gottardi, G., and Meier, W. M., Z. Krist., 119, 53 (1963).

${ }^{3}$ Kerr, I. S., Nature, 197, 1194 (1963).

\section{CHEMISTRY}

\section{A Novel Form of Co-ordination of Acetyl- acetone to Platinum(II)}

THE complex $\mathrm{K}\left[\mathrm{Pt}(\mathrm{acac})_{2} \mathrm{Cl}\right]$ has recently been shown to contain two different typos of acetylacotone groups ${ }^{\mathbf{1}}$; one being bonded as the conventional oxygen bidentate group and the othor through the $\gamma$-carbon atom of the acetyl. acetone (I). On acidification a bright yollow complex (II) separates which is sensitive to light. The 'acid' complox is sparingly soluble in water, but readily dissolvos in organic solvents. On standing for prolonged periods in benzene, a red binuclear complex di- $\mu$-chloro bis(acetylacetonato) diplatinium II is formed.
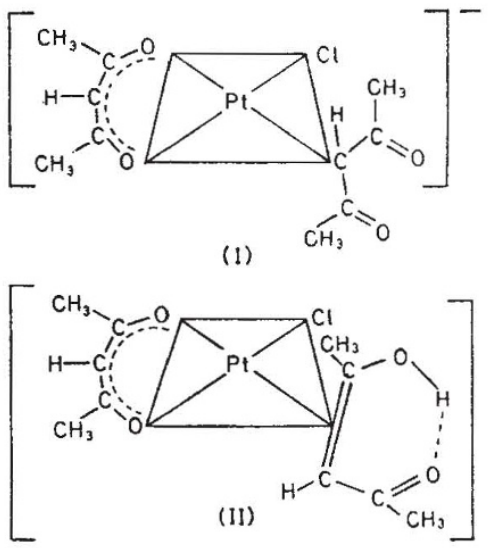

The infra-red and nuclear magnetic resonance spectra of the complex (II) indicate a different type of motalacetylacetone bonding is present and is in agreement with a structure (II). The high-frequency carbonyl band, in the infra-rod spectrum of the potassium salt, at $1,690 \mathrm{~cm}^{-1}$, which is associated with the free carbonyl groups, is lowerod in the 'acid' salt to $1,645 \mathrm{~cm}^{-1}$. 'The $\mathrm{C}-\mathrm{H}$ in plane deformation frequencies in the region $1,100-1,200$ $\mathrm{cm}^{-1}$ are modified, and the spectrum shows a very broad band in the $3,100 \mathrm{~cm}^{-1}$ region, which may be associated with an $\mathrm{O}-\mathrm{H}$ vibration. In agreement with this the band is shifted in the deutero complex to $2,200 \mathrm{~cm}^{-1}$. The general position and shape of this band are indicative of the presence of considerable hydrogen bonding in the system, as normally found for the enolic form of $\beta$ diketones.

The proton magnetic resonance spectrum of the potassium salt shows two soparate sets of methyl protons of equal intensity. The splitting of the methyl protons by coupling with platinum was readily observable for one group ( $J_{\mathrm{Pt}-\mathrm{II}}=3.8$ c.p.s.) but not for the other. Two further signals corresponding to the two $\gamma \mathrm{C}-\mathrm{H}$ protons were observed at 5.47 p.p.m. and 5.63 p.p.m. relative to tetramethylsilane. Tho former signal was coupled to the platinum spin with $J_{\mathrm{Pt}-\mathrm{HI}}=60 \mathrm{c.p} . \mathrm{s}$. and may be associated with the hydrogen-carbon system directly bonded to the platinum, the corrosponding coupling constant for methyl-platinum IV compounds being reported ${ }^{2}$ as 77 c.p.s. The 'acid' complex showed three sots of methyl protons in the ratio of $2: 1: 1$ with chemical shifts of 1.92 , $2 \cdot 06$, and 2.63 p.p.m. relative to tetraothylsilane. The presence of a hydrogen resonance at 12.47 p.p.m. due to 